\title{
Calcium-containing phosphopeptides pave the secretory pathway for efficient protein traffic and secretion in fungi
}

\author{
Juan F Martín
}

\begin{abstract}
Casein phosphopeptides (CPPs) containing chelated calcium drastically increase the secretion of extracellular homologous and heterologous proteins in filamentous fungi. Casein phosphopeptides released by digestion of alpha - and beta-casein are rich in phosphoserine residues (SerP). They stimulate enzyme secretion in the gastrointestinal tract and enhance the immune response in mammals, and are used as food supplements. It is well known that casein phosphopeptides transport $\mathrm{Ca}^{2+}$ across the membranes and play an important role in $\mathrm{Ca}^{2+}$ homeostasis in the cells.

Addition of CPPs drastically increases the production of heterologous proteins in Aspergillus as host for industrial enzyme production. Recent proteomics studies showed that CPPs alter drastically the vesicle-mediated secretory pathway in filamentous fungi, apparently because they change the calcium concentration in organelles that act as calcium reservoirs. In the organelles calcium homeostasis a major role is played by the pmr 1 gene, that encodes a $\mathrm{Ca}^{2+} / \mathrm{Mn}^{2+}$ transport ATPase, localized in the Golgi complex; this transporter controls the balance between intra-Golgi and cytoplasmic $\mathrm{Ca}^{2+}$ concentrations. A Golgi-located casein kinase (CkiA) governs the ER to Golgi directionality of the movement of secretory proteins by interacting with the COPII coat of secretory vesicles when they reach the Golgi. Mutants defective in the casein-2 kinase CkiA show abnormal targeting of some secretory proteins, including cytoplasmic membrane amino acid transporters that in ckiA mutants are miss-targeted to vacuolar membranes.

Interestingly, addition of CPPs increases a glyceraldehyde-3-phpshate dehydrogenase protein that is known to associate with microtubules and act as a vesicle/membrane fusogenic agent. In summary, CPPs alter the protein secretory pathway in fungi adapting it to a deregulated protein traffic through the organelles and vesicles what results in a drastic increase in secretion of heterologous and also of some homologous proteins.
\end{abstract}

Keywords: Protein secretion, Casein phosphopeptides, Calcium binding, Calcium homeostasis, Secretory vesicles, Protein sorting, Protein targeting, Fusogenic activity, Casein kinase, Filamentous fungi

\section{Introduction}

What are casein phosphopeptides? Role in calcium transport in the intestinal tract

Casein phosphopeptides (CPPs) are bioactive peptides derived from casein which are rich in phosphoserine. Bioactive peptides were first discovered in milk, yogurt and casein during early studies on infant nutrition [1-3]. CPPs are present in milk from all studied mammalians but usually we refer to those obtained from bovine casein

Correspondence: jf.marm@unileon.es

Área de Microbiología, Facultad de Ciencias Biológicas y Ambientales, Universidad de León, 24071 León, Spain since they are the best known [4] and because they are available commercially [5]. In recent years they have been extensively studied [6,7].

The CPPs have gastrointestinal activities and enhance the immune response in rats and in humans. They are used as diet supplements for specific nutritional or medical uses in Japan and some western countries. Due to their high phosphoserine content CPPs form complexes with $\mathrm{Ca}^{2+}$ through ionic interactions and they provide increased calcium bioavailability by maintaining $\mathrm{Ca}^{2+}$-phosphopeptides in a soluble form and by favouring $\mathrm{Ca}^{2+}$ transport through the intestinal walls [8-10]. The degree 
of $\mathrm{Ca}^{2+}$ binding is directly related to the number of phosphoserine residues in each CPP.

The phosphoserine residues are partially hidden inside the globular casein alfa and beta molecules but they became exposed when they are released by tryptic digestion of casein [11]. There are several CPPs derived from casein but the best known are the so-called " $\beta$-casein $4 \mathrm{P}$ (1-25)" that corresponds to the N-terminal 25 amino acids of $\beta$-casein, " $\alpha \mathrm{S} 1$ and $\alpha \mathrm{S} 2$ casein 4-P (1-21)" and " $\alpha \mathrm{S} 2$ casein 4-P (46-70)" (all of them with four phosphoserine residues) and " $\alpha \mathrm{S} 2-\mathrm{P}$ (59-79)" containing five phosphoserine residues [10] . Studies of chemically synthesized peptides showed that the presence of the tripeptides serP-Leu-serP and/or serP-serP-serP stimulates proliferation of lymphocytes [12].

\section{Commercial phosphopeptides preparation and phosphopeptide enrichment and purification}

Different degrees of purification of specific phosphopeptides are required for use as protein secretion enhancers in microbial fermentations or for the health and food-grade additives. Only for human medical applications, as inmunostimulants, may pure phosphopeptides be required.

Commercial preparations of CPPs in Japan and Europe are obtained by careful controlled hydrolysis of bovine casein with purified trypsin [13] or with successive digestions with pepsin and trypsin [11].

The available commercial preparations contain a mixture of phosphoserine-rich peptides including $\alpha \mathrm{S} 2$ (1-21) (or 1-32, depending on the manufacturer) [10] and $\beta$ - casein (1-25) and other poorly phosphorylated and unphosphorylated peptides. To increase the content of phosphoserine-rich peptides, CPPs preparations are enriched by several techniques [14].

\section{Phosphopeptides enrichment}

As indicated above, for medical uses or for research purposes phosphorylated peptides need to be enriched and purified. Many proteins in all living beings are reversibly phosphorylated and the phosphorylation/dephosphorylation degree is an important regulatory parameter for these proteins $[15,16]$. In eukaryotic cells substrate proteins are mainly phosphorylated at the hydroxyl group of some serine, threonine and tyrosine residues by protein kinases and dephosphorylated by protein phosphatases. The interest in the identification of the phosphorylation site(s) of the proteins has led to the development of different procedures for enrichment of phosphorylated proteins and peptides (the so-called phosphoproteome). Most of these procedures rely on inmobilized metal affinity chromatography (IMAC) [17-19] or filtration through strong cation exchange resins and strong anion exchangers [20].
A simple enrichment procedure is to precipitate the phosphopeptides with calcium [14]. More recently an efficient phosphopeptide enrichment method has been reported that combines an step of precipitation with calcium phosphate followed by IMAC using either Fe(III)- or TiO2inmobilized columns [21,22].

These techniques allow enrichment of phosphopeptides that may be later resolved by HPLC and characterized by high resolution LC/MS [23,24], coupled with dephosphorylation treatments with phosphatases if required to locate the position of the phosphorylated amino acids [23]. A mass $(\mathrm{m} / \mathrm{z})$ difference of 80 in the positive ion mode between the untreated and dephosphorylated peptide indicates the presence of a phosphate group in a CPP molecule.

\section{Fungi as host for secretion of homologous and heterologous proteins}

Many proteins, particularly enzymes, need to be produced at large scale for the food and chemical industries and also for specific medical applications [25-27]. Several filamentous fungi, particularly members of the genus Aspergillus $[28,29]$ and to a lower extent some species of Trichoderma and Penicillium (e.g. Penicillium roqueforti) are known to produce very large amounts of homologous proteins (up to $20 \mathrm{~g} /$ liter). This is the case of glucoamylase and $\alpha$-amylase in Aspergillus niger [30]. Other related Aspergillus species include Aspergillus awamori $[31,32]$ and Aspergillus oryzae [33]. For some applications in the food industry Penicillium roqueforti, Penicillium nalgiovense or Penicillium chrysogenum [34] may be also useful. All these fungi have been utilized extensively in food processiong and are considered to be GRAS (generally recognized as safe) organisms.

In addition to their high protein secretion capability filamentous fungi have other advantages as hosts for large scale production of enzymes, namely: i) fungi grow rapidly in a variety of culture media, ii) they produce correctly folded proteins, and iii) in fungi post-translational modifications of enzymes are similar to those that occur in animal cells. Also similar are the problems related to protein traffic through the vesicle-mediated system.

However, when animal or plant proteins (e.g. thaumatin) [21] or heterologous microbial proteins are expressed in the above mentioned fungal host strains, yields of the heterologous proteins are much lower than those of homologous proteins (amylases, proteases or lipases) in the same strains and are usually in the range of 10 to a few hundred mg of protein per liter of culture. The reason for this low yield is frequently the limitation of the mechanisms of protein folding and posttranslational protein modifications that are required for the protein to be transported by the organelle/vesicle-medianted transport in the secretory pathway. These limitations are bypassed (at least partially) by the action of the CPPs (see below). 
The limitations observed in expression of heterologous genes have been widely addressed by several research groups including the use of strong constitutive and inducible promoters $[27,30]$ and the construction of synthetic genes with optimal codon usage for Aspergillus [35-37] and is not further discussed.

\section{CPPs produce a drastic increase in the secretion of chymosin and other proteins in Aspergillus}

During studies on the production of the milk-clotting enzyme chymosin in Aspergillus, using a synthetic chy gene (encoding the bovine chymosin) with optimized codon usage [35], it was found that the production of chymosin was highly dependent on the addition of casein to a defined medium even though the medium contained asparragine as nitrogen source and glucose and glycerol as carbon sources. Later, the stimulation by casein was shown to be due to the phosphopeptides present in the casein that are released by the Aspergillus proteases [38]. Several plant derived proteins (peptones) do not exert the stimulatory effect on chymosin production, although a clear stimulation was exerted by other animal protein, the bovine seroalbumin. The bovine casein and seroalbumin appear to be richer in phosphoserine peptides than plantderived peptones.

The stimulatory effect of casein on chymosin production is not exerted by casein hydrolysates (casamino acids). This result might be explained by the different mechanisms of internalization of the phosphopeptides and the free amino acids (see below). Dephophorylated casein does not exert the stimulatory effect indicating that the drastic increase in chymosin production is due to the phosphorylated casein peptides. Interestingly pure phosphoserine does not produce any effect on protein secretion, in agreement with the observations of Otani et al. [12] on immunoglobulin production, suggesting that the stimulatory effect is due to the phosphorylated casein peptides and not to the free phosphoserine. Indeed, these authors [12] concluded that the presence of two or three adjacent (or separated by a single amino acid) phosphoserines in a peptide is required for the biological activity of CPPs.

The stimulatory effect of CPPs is not exerted at the transcriptional level. Northern analysis of expression of the chy gene in constructions using two different fungal promoters showed no changes in transcription of the chy gene following adition of CPPs. However, the increased secretion of this heterologous protein was confirmed by Western analysis using anti-chymosin antibodies and proteomic studies [38]. All the evidence available suggests that the stimulatory effect of CPPs is due to an activation of the vesicle-mediated transport system of secretory proteins.

\section{A global view of the secretory pathway: from the endoplasmid reticulum to the extracellular space}

The protein secretory route is a compartimentalized pathway [39] in which ribosomally synthesized proteins are finally targeted to the cell membrane and released to the extracellular space by an exocytosis mechanism, involving fusion of secretory vesicles to the cell membrane. The secretory proteins are transferred from one membrane enclosed organelle to vesicles and then to another organelle, and finally again through vesicles to the extracellular medium (Figure 1). The compartimentalization in different membrane-bound organelles or in vesicles serves to perform structural modifications of secretory proteins by modifiying enzymes residing in each compartment, thus avoiding competing modifying activities. Transfer of secretory proteins between organelles or between one organelle and the external cell space involves the packaging of appropriately folded, modified and oligomerized secretory proteins into distinct types of membrane-bound vesicles that ferry the proteins to different target sites.

The secretory protein pathway in yeast and filamentous fungi is similar in many respects to the protein secretion system in animal cells except that in filamentous fungi protein secretion is concentrated in the region near the tip of the hyphae. In the first step proteins containing a signal peptide at their $\mathrm{N}$-terminal end $[40,41]$ are recruited and transported into the endoplasmic reticulum (ER), concomitantly with cleavage of the signal peptide, by resident signal peptidases. In the ER the secretory proteins are adequately folded and modified by glycosylation and phosphorylation with the help of chaperones and foldases (such as $\mathrm{BiP}$ ) and glycosylating and phosphorylating enzymes.

\section{The protein- $\mathrm{Ca}^{2+}$ gel: a role of $\mathrm{BiP}$ and $\mathrm{Ca}^{2+}$ on folding and packaging of secretory proteins}

One of the ER-resident proteins, the chaperone BiP, has a $\mathrm{Ca}^{2+}$ binding activity and binds also to the nascent polypeptides being inserted into the ER lumen. Due to these activities BiP binds simoultaneously to the incompletely folded nascent proteins in the ER and to calcium, forming a gel, together with the other $\mathrm{Ca}^{2+}$-binding ER-resident proteins. The nascent proteins in the gel matrix are retained in the ER-lumen allowing them to be properly folded.

The $\mathrm{Ca}^{2+}$-protein gel binds to the phospholipids in the ER stabilizing the membrane and preventing undue vesicle budding from the ER. CPPs contain $\mathrm{Ca}^{2+}$ and bind to phospholipids [9], and they may act also in modulating the vesicles stability. When the nascent protein is properly folded and processed, the BiP protein is released from the protein$\mathrm{Ca}^{2+}$ gel, and specific local areas of the ER membrane are desestabilized allowing vesicle budding (Figure 1). The properly folded nascent protein is packaged in vesicles and 


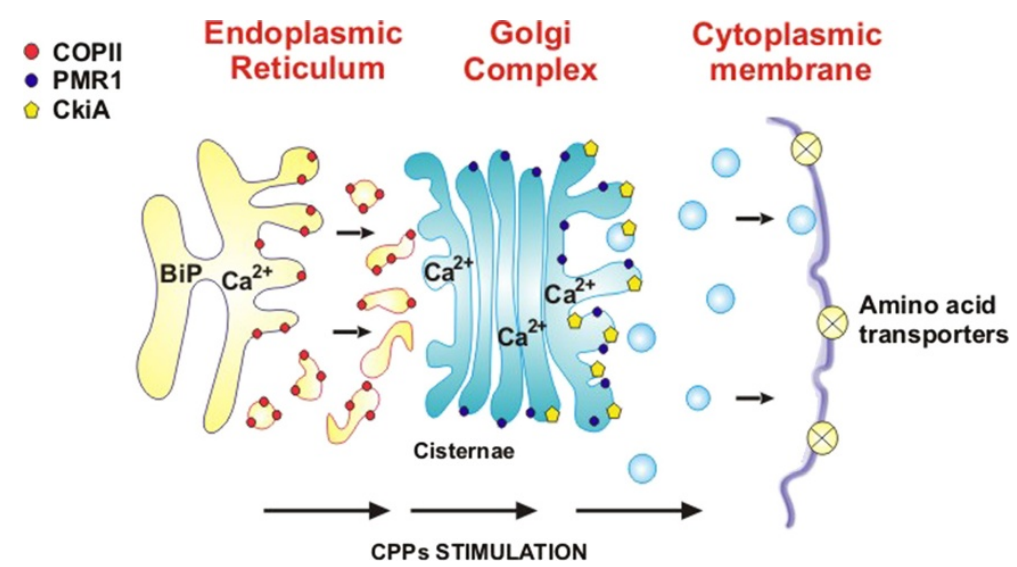

Figure $1 \mathrm{Global}$ view of the protein secretory pathway in filamentous fungi showing the location of the COPII complex in coated vesicles budding from the ER and merging to the Golgi complex where the CkiA (casein kinase) is involved in the vesicle coat removal and fusion of vesicles with the Golgi. The PMR1 $\mathrm{Ca}^{2+} / \mathrm{Mn}^{2+}$ transporter ATPase is located in the Golgi membranes. Finally the amino acid permeases located in the cytoplasmic membrane are shown. The targeting of these amino acid permeases is governed by CkiA. The CPPs produce an overall stimulation of the forward traffic of secretory proteins by altering the $\mathrm{Ca}^{2+}$ concentration gradients in the organelles (solid arrow in the botton, see text for details).

ferried to the Golgi complex or to alternative destinations in other membrane-bound systems in the cell, including the cytoplasmic membrane.

After leaving the ER the proteins are chanelled to the cisternae of the Golgi complex. The use of protein labeled with green or red fluorescent proteins (GFP or DsRed) combined with cnfocal fluorescence microscopy has allowed tracking of the proteins during transit from the ER to Golgi. Contrary to initial belief on the packaging in spherical vesicles, it has been evidenced that the secretory proteins are trapped in tubular structures that move directionally along actin microtubules following curvilinear paths. These pre-Golgi tubular cisternae finally are converted to the true Golgi complex. Some additional protein modifications occur in the Golgi complex, particularly extension of the carbohydrate chains or trimming down of the glycoproteins sugar chains.

\section{Secretory chekpoints \\ CPPs cause a checkpoint bypass}

The secretory proteins in the ER are folded with the help of the calcium-binding protein BiP [42]. Each packaging step into different vesicles serves as a checkpoint of quality control of the secretory proteins. Only those proteins that are adequately folded, oligomerized and processed according to the specific requirements of each class of carrier vesicles are packaged. Other proteins will be retained for refolding or, alternatively, targeted to vacuoles for recycling or degradation.

The packaging of the secretory proteins when leaving the ER is considered to be a major checkpoint since not all ER proteins are allowed to proceed to the Golgi complex. Traffic of proteins in vesicles from the ER to the
Golgi complex requires GTP and $\mathrm{Ca}^{2+}$ ions. Post-Golgi checkpoints are also likely to exist since mutants in late steps of the secretory pathway are known [43] that alter the secretion process.

The level of $\mathrm{Ca}^{2+}$ in the cytoplasm varies depending on several nutritional parameters and appears to play an important role in driving the movement of secretory vesicles through the hyphae $[44,45]$. In yeast and mammalian cells the ER acts as a $\mathrm{Ca}^{2+}$ reservoir. There are four $\mathrm{Ca}^{2+}$-binding proteins (one of them $\mathrm{BiP}$ ) that maintain a high $\mathrm{Ca}^{2+}$ concentration (up to three orders of magnitude) inside the ER. This concentration of $\mathrm{Ca}^{2+}$ in the ER is created by a membrane ATPase that stablishes an ion gradient across the membrane using ATP. The stored $\mathrm{Ca}^{2+}$ can be released by the action of inositol-triphosphate $[\operatorname{ins}(1,4,5)-\mathrm{P} 3]$. This compound is considered to be the controller of the organelle $\mathrm{Ca}^{2+}$ reservoir under normal physiological conditions [46].

Interestingly, the calcium concentration in the cytoplasm and the ER can also be modified by calcium ionophores independently of the role of ins(1,4,5)-P3. Calcium ionophores or mutations that impair the distribution of intracellular $\mathrm{Ca}^{2+}$ alter the retention of ER-resident proteins, such as GRP94, and allow indiscriminated secretion of ER resident and normal secretory proteins. One yeast mutant altered in the PMR1 gene, which encodes $\mathrm{a} \mathrm{Ca}^{2+}$ ion transporter, shows poor growth in $\mathrm{Ca}^{2+}$-limited medium and is sensitive to the $\mathrm{Ca}^{2+}$-chelating agent EGTA [47]. In this mutant ER-resident proteins are packaged together with normal secretory proteins resulting in abnormally increased protein secretion. Even incompletely glycosylated proteins that normally would be retained in the ER, are secreted in this mutant. 
This evidence led Sambrook [39] to propose that alteration of $\mathrm{Ca}^{2+}$ levels in the organelles versus the cytoplasm is the signal that triggers formation of secretory vesicles and their transport to the final destination. If the $\mathrm{Ca}^{2+}$ concentration change is too drastic, abnormal packaging of both secretory proteins and ER-resident proteins occurs. As mentioned above CPPs contain chelated $\mathrm{Ca}^{2+}$ and introduce this ion through the cell membrane [8] and they likely alter the intracellular $\mathrm{Ca}^{2+}$ concentration, producing an effect similar to that of PMR1 mutations in Saccharomyces cerevisiae.

The BiP protein (GRP78 in mammals) is an ER-resident calcium binding protein that responds to the intracellular $\mathrm{Ca}^{2+}$ ion concentration and also to the level of unfolded or malfolded protein (triggering the so-called unfolded protein response, UPR) [48]. Both $\mathrm{Ca}^{2+}$ and the unfolded protein levels regulate expression of the bipA gene through binding of the $\mathrm{C} 1$ transcriptional factor. This factor recognizes a GGAGG sequence adjacent to the CCAAT promoter region. Binding in vitro of the $\mathrm{C} 1$ factor to the GGAGG sequence decreases in the presence of high $\mathrm{Ca}^{2+}$ concentration and therefore, expression of the $\operatorname{bip} A$ gene is increased at lower intracellular $\mathrm{Ca}^{2+}$ concentration [49].

\section{The PMR1 protein of fungi: a $\mathrm{Ca}^{2+} / \mathrm{Mn}^{2+}$ ion pump involved in the secretory pathway, located in the Golgi and Golgi-like structures}

The early work of Rudolph et al. [47] established that the previously sequenced yeast gene named PMR1, that affected the secretion of extracellular proteins was a $\mathrm{Ca}^{2+}$ ion pump similar to those of mammalian cells. Deletion of the PMR1 gene in S. cerevisiae resulted in mutants that are unable to perform the protein outer glycosylation that is usually made in the Golgi.

S. cerevisae does not secrete efficiently heterologous mammalian proteins such as urokinase and bovine chymosin, apparently because these proteins are not properly modified and folded. Interestingly, yeast PMR1 mutants secrete these heterologous proteins more efficiently and unspecifically [50]. Also the endogenous yeast invertase, a glycosylated enzyme is more efficiently secreted in the PMR 1 mutants, although the secreted invertase lacks the branched mannose outer residues that are added during passage through the Golgi. These results suggest that alteration of the $P M R 1$-encoded $\mathrm{Ca}^{2+}$ ionpump results in incompletely glycosylated proteins and more efficient packaging and secretion of these incompletely glycosylated forms.

Antebi and Fink [50] using cell fractionation studies observed that the bulk of Pmr1 protein co-localizes with Golgi markers (Figure 1) but a fraction of it was proposed to be located in Golgi-like structures. Null PMR1 mutants showed growth deffects which were suppressed by millimolar concentrations of $\mathrm{Ca}^{2+}$. This led to propose that
PMR1 encodes a $\mathrm{Ca}^{2+}$ ion pump. Later Dürr et al. [51] observed that the growth defects of PMR 1 mutants were also reversed by addition of $\mathrm{Mn}^{2+}$, suggesting that this gene encodes a dual $\mathrm{Ca}^{2+} / \mathrm{Mn}^{2+}$ pump that accumulates these ions in the Golgi and Golgi-like complexes. Okorokov and Lehle [52] confirmed that the PMR1 protein localizes in the Golgi but observed that null PMR1 mutants still contain $50 \%$ of a PMR1-like activity. They concluded that there is a second $\mathrm{Ca}^{2+}$ ion transporter located in the ER and observed considerable redistribution of membrane located enzyme activities in the PMR1 mutants [53]. Mutations of the PMR1 gene and functional analysis of the mutant proteins suggested the involvement of some amino acids side chains of one transmembrane spanning domain (TMS-6) in binding $\mathrm{Ca}^{2+}$ ions $[54,55]$.

The PMR1 protein is a member of the SPCA (secreting pathway calcium ATPases family) that delivers $\mathrm{Ca}^{2+}$ ions to the intracellular organelles, particularly to the Golgi compartment $[47,50,51,53,54,56]$.

Based on the yeast evidence recent studies have focused on the role of the fungal pmr1 gene in $\mathrm{Ca}^{2+}$ homeostasis. This ion has an important role on the hyphae filamentous type of growth [57-60]. Recently Bowman et al. [61] have characterized two different mutants of the model fungus Neurospora crassa, one of them $(\Delta p m r 1)$ completely deleted in the pmr1 gene and the other containing specific nucleotide changes in this gene. Both mutants showed poor growth with highly branched hyphae and required $\mathrm{Ca}^{2+}$ and $\mathrm{Mn}^{2+}$ for optimal growth. The $\Delta p m r 1$ mutant showed a drastic reduction (of $80 \%$ ) in the accumulation of intracellular $\mathrm{Ca}^{2+}$ as compared to the wild type parental strain. The morphological defects could be partially reversed by $\mathrm{Mn}^{2+}$, although this ion did not affect the reduction of $\mathrm{Ca} 2+$ in the mutant, suggesting that the morphological effects caused by both $\mathrm{Ca}^{2+}$ and $\mathrm{Mn}^{2+}$ [62] are different from the specific effects on protein secretion caused by changes in calcium homeostasis.

The $N$ crassa Pmr1 $\mathrm{Ca}^{2+}$ ATPases belong to the PMCA subfamily (plasma membrane $\mathrm{Ca}^{2+}$ ATPases) of secretory ATPases. In the genomes of different filamentous fungi; there are from two to six $\mathrm{Ca}^{2+}$ ATPases that are located in the ER, the Golgi, the vacuolar membrane or other membrane systems [61-63].

Studies on the pmr1 gene of Aspergillus fumigatus [64] revealed similar effects of the pmr1 mutation, resulting in slow growth and high branching of hyphae; these defects were suppressed by supplementing the medium with a high $\mathrm{Ca}^{2+}$ concentration. In contrast, the pmr1 mutant of Aspergillus niger has no significant effect on morphological differentiation of this fungus, although growth of the mutant was stimulated by adding calcium $[65,66]$. Further research is needed to clarify possible differences in the control of calcium homeostasis between different filamentous fungi $[66,67]$. 
Tha addition of CPPs to A. awamori cultures mimics the secretion-enhancing effect of pmrl mutations, suggesting that CPPs act by altering the $\mathrm{Ca}^{2+}$ homeostasis in the cells.

\section{COPII, a complex of proteins forming the vesicle coat is involved in ER to Golgi protein traffic}

During the decades from 1990 to 2010 a series of important advances in our understanding of vesicle-mediated protein traffic were made. They contributed to the understanding of the enhanced secretion of extracellular proteins [68]. Using in vivo studies with yeast mutants and in vitro reconstitution experiments with cell fractions, several research groups contributed significant advances $[69,70]$. Based on genetic evidence and reconstitution experiments Seaman and Robinson [71] showed the involvement of a vesicle coat formed by Sec proteins that is required for vesicle buding from the ER. It was named COPII (coat complex II) to distinguish it from the COPI complex involved in vesicle formation at the Golgi.

Mossessova and coworkers [72] proved that the nucleotide GTP is required for vesicle formation due to the involvement in COPII of the small GTP-binding protein Sar1p. The COPII complex is assembled at the ER when the activated form of the GTPase Sar1p is recruited by the Sec23p/sec24 proteins as Sar1p-GTP interacts with the sec23p and the GTPase-activating protein (GAP). Polymerization of the coat requires proteins Sec13p/ sec31p (outer shell proteins) that are recruited by interaction with the sec $23 \mathrm{p} / \mathrm{sec} 24 \mathrm{p}$ complex. The initial interaction of a coated vesicle with the target membrane is mediated by a class of proteins named "tethers" that work together with the Ras1 family GTPase. The tethering factor TRAPP1 is a protein that binds and activates the Ras1 GTPase Ypt1p [73,74].

\section{Interaction of the TRAPP1 factor with the sec $23 p$ of the membrane and a casein kinase determines the direction of vesicle traffic}

The directionality of the traffic from ER to Golgi (forward traffic) or from Golgi to ER (backward or retrograde movement) has remained obscure for years until Lord et al. [75] established that the involvement of a casein kinase Hrr25p is essential for the directionality of the vesicle traffic. A decrease of the Hrr25 casein kinase activity in a yeast mutant suppreses the vesicle budding deffect in this mutant [76]. Interestingly this casein kinase, located exclusively in the Golgi, upon vesicle arrival to the Golgi, displaces the TRAPP1 factor from the coat Sec23p and phosphorylates the Sec23p/Sec24p proteins of the vesicle coat [75]. The unmasked COPII in the coated vesicle is then allowed to pair with the target (t-SNARE) docking protein (Sec22p) in the Golgi to discharge its cargo content. The sequential binding to
COPII of Sar1p, then of TRAPP1 and finally the interaction with the casein kinase assures the forward directionality of the vesicle traffic and prevents the retrograde movement and the fusion of the vesicle back to the ER, since the casein kinase is located in the Golgi. Indeed, fluorescent protein targeting analysis of the Hrr25p casein kinase revealed that most of it (95\%) co-localizes with pre-Golgi (punctuated particles) and late Golgi protein markers.

The Hrr25 kinase belongs to a family of casein kinases (Cki), that phosphorylates casein and other proteins at serine/threonine residues and its activity has implications on membrane protein traffic $[77,78]$. The casein kinase Hrr25p has an orthologue CK1p in the Golgi of mammals that is also involved in the vesicle traffic from ER to Golgi [77].

Apostolaki et al. [79] reported that three different strains of Aspergillus nidulans that were initially isolated as defective in amino acid transport and resistance to amino acid analogues were indeed mutants defective in the Hrr25p homologue casein kinase (named CkiA in A. nidulans). These mutations in the CkiA gene correlated with a rerouting of two membrane amino acid transport proteins (AgtA for glutamate and PrnB for proline). In the CkiA mutant these transporter proteins are targeted to the vacuoles instead of the cytoplasmic membrane and the absence of these transporters in the cell membrane explains the inability of the mutant strains to transport and utilize these amino acids or their toxic analogues.

The amino acid transporter proteins that are redirected to the vacuole belong to a well characterized family of amino acid transporters all of which share a topology containing 12 transmembrane spanning domains (TMS). The highly conserved structure of those transporter proteins suggests that this topology may have a role in the passage of these transporters through the ER and Golgi and in their final insertion in the cell membrane [79].

The Cki homologue Hrr25p in S. cerevisiae is known to phosphorylate the sec23p component of COPII [75]. It seems unlikely that the Aspergillus casein kinase activity modifies the mechanism of the COPII-mediated ER to Golgi directionality of secretory protein traffic that seems to be conserved in different eukaryotic cells. Rather, the phosphorylation leads to redirecting the destination of the membrane targeted proteins [79]. Similarly, in the light of present evidence the casein phosphopeptides are likely to be protein traffic signals that mimic the role of peptide substrates of the casein kinase in protein traffic (see proteomic studies below).

Physiological and proteomic studies on the effect of CPPs In filamentous fungi growth takes place by hyphal tip extension. The hyphal tip is packed with vesicles and some 
membrane enclosed organelles, and it is known that cell wall biosynthetic enzymes and other nutrient hydrolytic enzymes are secreted at the tip or in the region near the tip [80]. In $N$. crassa a $\mathrm{Ca}^{2+}$ gradient is known to occur around those organelles $[44,45]$.

Early physiological studies related to the nutritional role of CPPs revealed that CPPs play an important role on the regulation of gastric enzyme secretion in young mammals $[8,12,13,81-84]$. These effects were associated with changes in $\mathrm{Ca}^{2+}$ transport in the gastrointestinal tract cells [9]. CPPs also trigger the secretion of lynfokines in epithelial cell cultures [7].

Recently proteomics studies using cultures of $A$. awamori showed that supplementation with CPPs resulted in a drastic increase in the secretion of cell-wall synthesizing enzymes and several other extracellular enzymes which are known to be secreted through the vesicle-mediated secretory pathway [38]. The secreted cell-wall synthesizing enzymes include two different glucanosyltransferases and a GPI-linked cell wall polymer-organizing protein. The extracellular enzymes include $\alpha$-amylase, glucoamylase, $\beta$-galactosidase, several proteases of Aspergillus and the engineered calf chymosin cloned into the fungal host. The secreted chymosin is increased 6.5-fold in CPP supplemented cultures with respect to the unsupplemented ones. The increased secretion of proteins is accompanied by a sharp decrease in the intracellular concentration of the precursor proteins of the secretory enzymes. Even ER-resident proteins such as BiP and other related chaperones of the heat-shock family (Hsp70 family) are depleted in CPPs supplemented cultures. Also an Hsp90 co-chaperone and a cyclophilin-like peptidyl-prolyl cis-trans isomerase that contributes to protein folding, are partially or totally depleted in the cells following CPPs addition. The same is true for the lectin chaperone calnexin. The underrepresentation of the chaperones in the intrancellular proteome of CPPsupplemented cells is probably due to the switch-off of the unfolded protein response (that in unsupplemented control cultures triggers the synthesis of $\mathrm{BiP}$ and other chaperones, [85]) since incompletely folded proteins are no longer retained in the ER.

\section{A key role for the protein glyceraldehyde-3-phosphate dehydrogenase induced by CPPs}

One of the overrepresented proteins in the proteome of CPPs-supplemented cells is a glyceraldehyde-3-phosphate dehydrogenase (GPDH). This protein, in addition to its well known role in glycolysis, has vesicle fusogenic activity, microtubule bundling and a microtubule phosphotransferase/kinase activity that appears to be related to $\mathrm{Ca}^{2+-}$ gradient during vesicle-mediated transport of secretory proteins [86-89]. This protein bundles microtubule in brain cells [87].
This GPDH has kinase/phosphotransferase activity. It is known that it autophosphorylates and also phosphorylates proteins in microsomes of skeletal nuucle cells [88]. GPDH has a $\mathrm{Ca}^{2+}$-dependent vesicle fusogenic activity in human neutrophils [89] and is involved in vesicle transport of secretory proteins during early transport of secretory proteins from ER into the Golgi complex $[90,91]$.

Since A awamori cells supplemented with CPPs show a high level of GPDH (38), the stimulation of vesicle transport and fusogenic activity of GPDH is probably one of the major effects of CPPs that that explains the enhanced protein secretion.

\section{From Golgi to the cell membrane and the extracellular medium}

Filamentous fungi grow by apical extension at a relatively high speed (up to $0.5 \mu \mathrm{m}$ per min) [92]. This implies that cell-wall precursors, cell wall synthesizing enzymes and other secretory proteins have to move relatively long distances in the hyphae [93] since it is well known that secretion of those enzymes concentrates at the apical and subapical regions [94-97]. Movement of the cargo-loaded vesicles proceeds along microtubule tracks [92] until it reaches the end of the microtubule where they merge with the cell membrane releasing their protein cargo.

\section{Endocytosis and possible internalization of CPPs}

The microtubule-guided secretion is coupled to endocytosis, a compensatory mechanism by which external peptides and proteins are engulfed by membrane fragments which are excised from the cell membrane. Following internalization, the endosomes and their protein/ peptide content play an important role in vesiclemembrane traffic in eukaryotic cells. Although endocytosis in fungi may occur in different locations in the hyphae all evidences suggest that it takes place largely in a subapical region, forming a characteristic endosome collar near the hyphae tip [98].

The mechanism(s) of CPPs internalization is still unknown; these compounds are highly charged. If casein phosphopeptides are taken up by endocytosis, their drastic effect on vesicle-mediated protein secretion can be easily explained.

During endocytosis the initial early endosomes move from the cell membrane to the nuclear periphery and this "centripetal" movement is in equilibrium with the microtubule-mediated "centrifugal" vesicle movement that is consistent with protein secretion. Whereas the centripetal movement is dynein-dependent the centrifugal motility along microtubules is regulated by kinesin. 
It is likely that internalized CPPs play a role in the regulation of kinesin and/or dynein, thereby driving the vesicles towards the cell membrane $[94,99,100]$. This model is consistent with the phosphorylating role of GPDH and with recent findings on membrane organelle distribution [101] in fungal cells [102,103].

\section{Future perspectives}

It is clear from the available data that secretion of heterologous proteins in S. cerevisiae is inefficient [104]. Addition of casein phosphopeptides has a dramatic effect on secretion of homologous, and particularly of heterologous proteins, in filamentous fungi. This evidence is reinforced by recent studies on proteomics of unsupplemented and CPPs-supplemented fungal cells. Supplementation leads to a drastic decrease of the intracellular content of secretory proteins resulting in a large increase of the extracellular forms of these proteins.

Casein phosphopeptides contain chelated $\mathrm{Ca}^{2+}$ ions and interact with membrane phospholipids. Although their internalization mechanism is unknown it may involve endocytosis [105]. One of the proteins overrepresented in CPPs-supplemented cells is glyceraldehyde-3phosphate dehydrogenase that has microtubule binding and vesicle-fusogenic activity. The enhancement of these activities as a response to CPPs addition explains the increased secretory vesicle traffic. CPPs seem to alter the distribution of intracellular membrane organelles favouring the forward (anterograde) movement of cargo loaded vesicles from ER to Golgi and then from Golgi to the cell membrane.

The vesicle movement guided on microtubules tracks is a likely target of regulation by $\mathrm{Ca}^{2+}$ and CPPs but more research is needed to clarify the molecular mechanisms of this regulation. Also a comprehensive understanding of the modification of $\mathrm{Ca}^{2+}$ levels in the organelles is needed.

Independent of the molecular mechanisms, inexpensive CPPs may be easily used to increase the production of homologous and heterologous proteins in filamentous fungi in cell factory processes. Optimization of the fermentation parameters in each case will help to improve the titers of the secreted proteins.

\section{Abbreviations}

CPPs: Casein phosphopeptides; SerP: Phosphoserine; GPDH: Glyceraldehyde-3-phosphate dehydrogenase; ER: endoplasmic reticulum; BiP: Binding protein (to unfolded nascent polypeptides).

\section{Competing interests}

The author declare that he has no competing interests.

\section{Acknowledgements}

I thank Dr. Paloma Liras for valuable scientific discussion and for the help in the preparation of this article and Drs. Katarina Kosalkova, Carlos G. Estrada and $C$. Barreiro for previous research work that allowed us to understand the action of the CPPS.
Received: 23 June 2014 Accepted: 1 August 2014

Published online: 10 September 2014

\section{References}

1. Reeves RE, Latour NG: Calcium phosphate sequestering phosphopeptide from casein. Science 1958, 128:472.

2. Clare DA, Swaisgood HE: Bioactive milk peptides: a prospectus. J Dairy Sci 2000, 83:1187-1195.

3. Kitts DD, Weiler KL: Bioactive proteins and peptides from food sources. Applications of bioprocesses used in islation and recovery. Curr Pharm Des 2003, 9:1309-1323.

4. Chabance B, Marteau P, Rambaud JC, Migliore-Samour D, Boynard M, Perrotin $P$, Guillet $R$, Jollès $P$, Fiat AM: Casein peptide release and passage to the blood in humans during digestion of milk or yogurt. Biochimie 1998, 80:155-165.

5. Hata I, Ueda J, Otani H: Inmunostimulatory action of a commercially available casein phosphopeptide preparation, CPPIII, in cell cultures. Milchwissenschaft 1999, 54:3-7.

6. Kawahara T, Otani H: Stimulatory effects of casein phosphopeptide (CPP-III) on mRNA expression of cytokines in Caco-2 cells. Biosci Biotechnol Biochem 2004, 68:1779-1781.

7. Kitts DD, Nakamura S: Calcium-enriched casein phosphopeptide stimulates release of IL- 6 cytokine in human epithelial intestinal cell line. J Dairy Res 2006, 73:44-48.

8. Mykkänen HM, Wasserman RH: Enhanced absorption of calcium by casein phosphopeptides in rachitic and normal chicks. J Nutr 1980, 110:2141-2148.

9. Kitts DD, Yuan YV: Caseinophosphopeptides and calcium bioavailability. Trends Food Sc Technol 1992, 3:31-35.

10. Kitts DD, Kwong WY: Calcium Availability of Diary Components. In Handbook of Functional Diary Products. Edited by Shortt C, O'brien J. New York: CRC Press; 2004:169-197.

11. Ono T, Takagi $Y$, Kunishi I: Casein phosphopeptides from casein micelles by successive digestion with pepsin and trypsin. Biosci Biotechnol Biochem 1998, 62:16-21.

12. Otani H, Watanabe T, Tashiro Y: Effects of bovine beta-casein (1-28) and its chemically synthesized partial fragments on proliferative responses and immunoglobulin production in mouse spleen cell cultures. Biosci Biotechnol Biochem 2001, 65:2489-2495.

13. Hirayama M, Toyota K, Yamaguchi G, Hidaka H, Naito H: HPLC analysis of commercial casein phosphopeptides (CPP). Biosci Biotechnol Biochem 1992, 56:1126-1127.

14. Reynolds EC, Riley PF, Adamson NJ: A selective precipitation purification procedure for multiple phosphoseryl-containing peptides and methods for their identification. Anal Biochem 1994, 217:277-284.

15. Hunter T: Signaling-2000 and beyond. Cell 2000, 100:113-127.

16. Manning G, Whyte DB, Martinez R, Hunter T, Sudarsanam S: The protein kinase complement of the human genome. Science 2002, 298:1912-1934.

17. Nühse TS, Stensballe A, Jensen ON, Peck SC: Large-scale analysis of in vivo phosphorylated membrane proteins by immobilized metal ion affinity chromatography and mass spectrometry. Mol Cell Proteomics 2003, 2:1234-1243.

18. Nühse TS, Peck SC: Peptide-based phosphoproteomics with immobilized metal ion chromatography. Methods Mol Biol 2006, 323:431-436.

19. Manteca A, Ye J, Sánchez J, Jensen ON: Phosphoproteome analysis of Streptomyces development reveals extensive protein phosphorylation accompanying bacterial differentiation. J Proteome Res 2011, 10:5481-5492.

20. Lim KB, Kassel DB: Phosphopeptides enrichment using on-line twodimensional strong cation exchange followed by reversed-phase liquid chromatography/mass spectrometry. Anal Biochem 2006, 354:213-219.

21. Larsen MR, Thingholm TE, Jensen ON, Roepstorff $P$, Jørgensen TJ: Highly selective enrichment of phosphorylated peptides from peptide mixtures using titanium dioxide microcolumns. Mol Cell Proteomics 2005, 4:873-886.

22. Zhang X, Ye J, Jensen ON, Roepstorff P: Highly efficient phosphopeptide enrichment by calcium phosphate precipitation combined with subsequent IMAC enrichment. Mol Cell Proteomics 2007, 6:2032-2042.

23. Talbo GH, Suckau D, Malkoski M, Reynolds EC: MALDI-PSD-MS analysis of the phosphorylation sites of caseinomacropeptide. Peptides 2001, 22:1093-1098.

24. Mann M, Jensen ON: Proteomic analysis of post-translational modifications. Nat Biotechnol 2003, 21:255-261. 
25. Demain AL, Vaishnav P: Production of recombinant proteins by microbes and higher organisms. Biotechnol Adv 2009, 27:297-306.

26. Peberdy JF: Protein secretion in filamentous fungi-trying to understand a higly productive black box. Trend Biotechnol 1994, 12:50-57.

27. Archer DB, Peberdy JF: The molecular biology of secreted enzyme production by fungi. Crit Rev Biotechnol 1997, 17:273-306.

28. van den Hombergh JP, van de Vondervoort PJ, Fraissinet-Tachet L, Visser J: Aspergillus as a host heterologous protein production: the problem of proteases. Trends Biotechnol 1997, 15:256-263.

29. Pel HJ, de Winde JH, Archer DB, Dyer PS, Hofmann G, Schaap PJ, Turner G, de Vries RP, Albang R, Albermann K, Andersen MR, Bendtsen JD, Benen JA, van den Berg M, Breestraat S, Caddick MX, Contreras R, Cornell M, Coutinho PM, Danchin EG, Debets AJ, Dekker P, van Dijck PW, van Dijk A, Dijkhuizen L, Driessen AJ, d'Enfert C, Geysens S, Goosen C, Groot GS, et al: Genome sequencing and analysis of the versatile cell factory Aspergillus niger. Nature 2007, 25:221-231.

30. Gouka RJ, Punt PJ, van den Hondel CA: Efficient production of secreted proteins by Aspergillus: progress, limitations and prospects. App/ Microbiol Biotechnol 1997, 47:1-11.

31. Faus I, del Moral C, Adroer N, del Río JL, Patiño C, Sisniega H, Casas C, Bladé J, Rubio V: Secretion of the sweet-tasting protein thaumatin by recombinant strains of Aspergillus niger var. awamori. Appl Microbiol Biotechnol 1998, 49:393-398.

32. Moralejo FJ, Cardoza RE, Gutiérrez S, Sisniega H, Faus I, Martín JF: Overexpression and lack of degradation of thaumatin in an aspergillopepsin A-defective mutant of Aspergillus awamori containing an insertion in the pepA gene. Appl Microbiol Biotechnol 2000, 54:772-777.

33. Machida M, Asai K, Sano M, Tanaka T, Kumagai T, Terai G, Kusumoto K, Arima T, Akita O, Kashiwagi Y, Abe K, Gomi K, Horiuchi H, Kitamoto K, Kobayashi T, Takeuchi M, Denning DW, Galagan JE, Nierman WC, Yu J, Archer DB, Bennett JW, Bhatnagar D, Cleveland TE, Fedorova ND, Gotoh O, Horikawa H, Hosoyama A, Ichinomiya M, lgarashi R, et al: Genome sequencing and analysis of Aspergillus oryzae. Nature 2005, 438:1157-1161.

34. Jami MS, García-Estrada C, Barreiro C, Abel-Alberto C, Salehi-Najafabadi Z, Martín JF: The Penicillium chrysogenum extracellular proteome. Conversion from a food-rotting strain to a versatile cell factory for white biotechnology. Mol Cell Proteomics 2010, 9:2729-2744.

35. Cardoza RE, Gutiérrez S, Ortega N, Colina A, Casqueiro J, Martín JF: Expression of a synthetic copy of the bovine chymosin gene in Aspergillus awamori from constitutive and $\mathrm{pH}$-regulated promoters and secretion using two different pre-pro sequences. Biotechnol Bioeng 2003, 83:249-259

36. van den Hondel CAMJJ, Punt PJ, van Gorcom RFM: Heterologous Gene Expression in Filamentous Fungi. In More Gene Manipulation in Fungi. Edited by Benner JW, Lasure LL. San Diego CA: Academic; 1991:396-428.

37. Dunn-Coleman NS, Bloebaum P, Berka RM, Bodie E, Robinson N, Armstrong G, Ward M, Przetak M, Carter GL, LaCost R: Commercial levels of chymosin production by Aspergillus. Biotechnology (N Y) 1991, 9:976-981.

38. Kosalková K, García-Estrada C, Barreiro C, Flórez MG, Jami MS, Paniagua MA Martín JF: Casein phosphopeptides drastically increase the secretion of extracellular proteins in Aspergillus awamori. Proteomics studies reveal changes in the secretory pathway. Microb Cell Fact 2012, 11:5.

39. Sambrook JF: The involvement of calcium in transport of secretory proteins from the endoplasmic reticulum. Cell 1990, 61:197-199.

40. von Heijne G: Patterns of Amino acid near signal-sequence clevage sites. Eur J Biochem 1983, 133:17-21.

41. von Heijne G: Signal sequences. The limits of variation. J Mol Bio/ 1985 184:99-105.

42. Gething MJ, Sambrook J: Transport and assembly processes in the endoplasmic reticulum. Semin Cell Biol 1990, 1:65-72.

43. Lyman SK, Schekman R: Binding of secretory precursor polypeptides to a translocon subcomplex is regulated by BiP. Cell 1997, 88:85-96.

44. Silverman-Gavrila LB, Lew RR: Regulation of the tip-high [Ca2+] gradient in growing hyphae of the fungus Neurospora crassa. Eur J Cell Biol 2001, 80:379-390.

45. Silverman-Gavrila LB, Lew RR: Calcium gradient dependence of Neurospora crassa hyphal growth. Microbiology 2003, 149:2475-2485.

46. Berridge MJ, Irvine RF: Inositol phosphates and cell signalling. Nature 1989, 341:197-205.

47. Rudolph HK, Antebi A, Fink GR, Buckley CM, Dorman TE, LeVitre J, Davidow LS, Mao Jl, Moir DT: The yeast secretory pathway is perturbed by mutations in PMR1, a member of a Ca2+ ATPase family. Cell 1989, 58:133-145.

48. Collén A, Saloheimo M, Bailey M, Penttilä M, Pakula TM: Protein production and induction of the unfolded protein response in Trichoderma reesei strain Rut-C30 and its transformant expressing endoglucanase I with a hydrophobic tag. Biotechnol Bioeng 2005, 89:335-344.

49. Roy B, Lee AS: Transduction of calcium stress through interaction of the human transcription factor CBF with the proximal CCAAT regulatory element of the grp78/BiP promoter. Mol Cell Biol 1995, 15:2263-2274.

50. Antebi A, Fink GR: The yeast $\mathrm{Ca}(2+)$-ATPase homologue, PMR1, is required for normal Golgi function and localizes in a novel Golgi-like distribution. Mol Biol Cell 1992, 3:633-654.

51. Dürr G, Strayle J, Plemper R, Elbs S, Klee SK, Catty P, Wolf DH, Rudolph HK: The medial-Golgi ion pump Pmr1 supplies the yeast secretory pathway with $\mathrm{Ca} 2+$ and $\mathrm{Mn} 2+$ required for glycosylation, sorting, and endoplasmic reticulum-associated protein degradation. Mol Biol Cell 1998, 9:1149-1162.

52. Okorokov LA, Lehle L: Ca(2+)-ATPases of Saccharomyces cerevisiae: diversity and possible role in protein sorting. FEMS Microbiol Lett 1998, 162:83-91.

53. Vandecaetsbeek I, Vangheluwe P, Raeymaekers L, Wuytack F, Vanoevelen J: The Ca2+ pumps of the endoplasmic reticulum and Golgi apparatus. Cold Spring Harb Perspect Biol 2011, doi:10.1101/cshperspect.a004184.

54. Wei Y, Chen J, Rosas G, Tompkins DA, Holt PA, Rao R: Phenotypic screening of mutations in Pmr1, the yeast secretory pathway Ca2+/Mn2 +-ATPase, reveals residues critical for ion selectivity and transport. J Biol Chem 2000, 275:23927-23932

55. Mandal D, Rulli SJ, Rao R: Packing interactions between transmembrane helices alter ion selectivity of the yeast Golgi Ca2+/Mn2 +-ATPase PMR1. J Biol Chem 2003, 278:35292-35298.

56. Missiaen L, Dode L, Vanoevelen J, Raeymaekers L, Wuytack F: Calcium in the Golgi apparatus. Cell Calcium 2007, 41:405-416.

57. Harold FM: Force and compliance: rethinking morphogenesis in walled cells. Fungal Genet Biol 2002, 37:271-282.

58. Jackson SL, Heath IB: Roles of calcium ions in hyphal tip growth. Microbiol Rev 1993, 57:367-382.

59. McGillviray AM, Gow NAR: The transhyphal electrical current of Neurospora crassa is carried principally by protons. J Gen Microbio/ 1987, 133:2875-2881.

60. Prokisch $H$, Yarden O, Dieminger M, Tropschug M, Barthelmess IB: Impairment of calcineurin function in Neurospora crassa reveals its essential role in hyphal growth, morphology and maintenance of the apical $\mathrm{Ca}^{2+}$ gradient. Mol Gen Genet 1997, 256:104-114.

61. Bowman BJ, Abreu S, Margolles-Clark E, Draskovic M, Bowman EJ: Role of four calcium transport proteins, encoded by nca-1, nca-2, nca-3, and cax, in maintaining intracellular calcium levels in Neurospora crassa. Eukaryot Cell 2011, 10:654-661.

62. Bowman BJ, Abreu S, Johl JK, Bowman EJ: The pmr gene, encoding a $\mathrm{Ca}^{2+}$-ATPase, is required for calcium and manganese homeostasis and normal development of hyphae and conidia in Neurospora crassa. Eukaryot Cell 2012, 11:1362-1370.

63. Bowman BJ, Draskovic M, Freitag M, Bowman EJ: Structure and distribution of organelles and cellular location of calcium transporters in Neurospora crassa. Eukaryot Cell 2009, 8:1845-1855.

64. Pinchai N, Juvvadi PR, Fortwendel JR, Perfect BZ, Rogg LE, Asfaw YG, Steinbach WJ: The Aspergillus fumigatus P-type Golgi apparatus $\mathrm{Ca}^{2+} / \mathrm{Mn}^{2+}$ ATPase PmrA is involved in cation homeostasis and cell wall integrity but is not essential for pathogenesis. Eukaryot Cell 2010, 9:472-476.

65. Bencina M, Bagar T, Lah L, Krasevec N: A PMR1-like calcium ATPase of Aspergillus fumigatus: cloning, identification and functional expression in S. cerevisiae. Fungal Genet Biol 2009, 46(Suppl 1):S93-S104.

66. Yang J, Kang HA, Ko SM, Chae SK, Ryu DD, Kim JY: Cloning of the Aspergillus niger pmrA gene, a homologue of yeast PMR1, and characterization of a pmrA null mutant. FEMS Microbiol Lett 2001, 199:97-102.

67. Soriani FM, Martins VP, Magnani T, Tudella VG, Curti C, Uyemura SA: A PMR1-like calcium ATPase of Aspergillus fumigatus: cloning, identification and functional expression in S. cerevisiae. Yeast 2005, 22:813-824.

68. van den Brink HJ, Petersen SG, Rahbek-Nielsen H, Hellmuth K, Harboe M: Increased production of chymosin by glycosylation. J Biotechnol 2006, 125:304-310. 
69. Pryer NK, Wuestehube LJ, Schekman R: Vesicle-mediated protein sorting. Annu Rev Biochem 1992, 61:471-516.

70. Rothman JE, Orci L: Molecular dissection of the secretory pathway. Nature 1992, 355:409-415.

71. Seaman MN, Robinson MS: Membrane traffic. Call for the COPs. Curr Biol 1994, 4:926-992.

72. Mossessova E, Bickford LC, Goldberg J: SNARE selectivity of the COPII coat. Cell 2003, 114:483-495.

73. Whyte JR, Munro S: Vesicle tethering complexes in membrane traffic. J Cell Sci 2002, 115:2627-2637.

74. Cai H, Yu S, Menon S, Cai Y, Lazarova D, Fu C, Reinisch K, Hay JC, Ferro-Novick S: TRAPPI tethers COPII vesicles by binding the coat subunit Sec23. Nature 2007, 445:941-944

75. Lord C, Bhandari D, Menon S, Ghassemian M, Nycz D, Hay J, Ghosh P, Ferro-Novick S: Sequential interactions with Sec23 control the direction of vesicle traffic. Nature 2011, 473:181-186.

76. Murakami A, Kimura K, Nakano A: The inactive form of a yeast casein kinase I suppresses the secretory defect of the sec12 mutant. Implication of negative regulation by the Hrr25 kinase in the vesicle budding from the endoplasmic reticulum. J Biol Chem 1999, 274:3804-3810

77. Milne DM, Looby P, Meek DW: Catalytic activity of protein kinase CK1 delta (casein kinase 1delta) is essential for its normal subcellular localization. Exp Cell Res 2001, 263:43-54.

78. Yu S, Roth MG: Casein kinase I regulates membrane binding by ARF GAP1. Mol Biol Cell 2002, 13:2559-2570.

79. Apostolaki A, Harispe L, Calcagno-Pizarelli AM, Vangelatos I, Sophianopoulou V, Arst HN Jr, Peñalva MA, Amillis S, Scazzocchio C: Aspergillus nidulans CkiA is an essential casein kinase I required for delivery of amino acid transporters to the plasma membrane. Mol Microbiol 2012, 84:530-549.

80. Collinge AJ, Trinci APJ: Hyphal tips of wild-type and spreading colonial mutants of Neurospora crassa. Arch Microbiol 1974, 99:353-368.

81. Schlimme $\mathrm{E}$, Meisel $\mathrm{H}$ : Bioactive peptides derived from milk proteins Structural, physiological and analytical aspects. Nahrung 1995, 39:1-20.

82. Lee YS, Noguchi T, Naito H: Intestinal absorption of calcium in rats given diets containing casein or amino acid mixture: the role of casein phosphopeptides. Br J Nutr 1983, 49:67-76.

83. Guilloteau P, Romé V, Delaby L, Mendy F, Roger L, Chayvialle JA: A new role of phosphopeptides as bioactive peptides released during milk casein digestion in the young mammal: regulation of gastric secretion. Peptides 2009, 30:2221-2227.

84. Hata I, Higashiyama S, Otani H: Identification of a phosphopeptide in bovine as1-casein digest as a factor influencing proliferation and immunoglobulin production in lymphocyte cultures. J Dairy Res 1998, 65:569-578

85. Lombraña M, Moralejo FJ, Pinto R, Martín JF: Modulation of Aspergillus awamori thaumatin secretion by modification of bipA gene expression. Appl Environ Microbiol 2004, 70:5145-5152.

86. Sirover MA: New insights into an old protein: the functional diversity of mammalian glyceraldehyde-3-phosphate dehydrogenase. Biochim Biophys Acta 1999, 1432:159-184.

87. Kumagai $\mathrm{H}$, Sakai $\mathrm{H}$ : A porcine brain protein ( $35 \mathrm{~K}$ protein) which bundles microtubules and its identification as glyceraldehyde 3-phosphate dehydrogenase. J Biochem 1983, 93:1259-1269.

88. Kawamoto R, Caswell A: Autophosphorylation of glyceraldehydephosphate dehydrogenase and phosphorylation of proteins from skeletal muscle microsomes. Biochemistry 1986, 25:657-661.

89. Hessler RJ, Blackwood RA, Brock TG, Francis JW, Harsh DM, Smolen JE: Identification of glyceraldehyde-3-phosphate dehydrogenase as a $\mathrm{Ca}^{2+}$-dependent fusogen in human neutrophil cytosol. J Leukoc Biol 1998, 63:331-336.

90. Tisdale EJ: Glyceraldehyde-3-phosphate dehydrogenase is required for vesicular transport in the early secretory pathway. J Biol Chem 2001, 276:2480-2486.

91. Presley JF, Cole NB, Schroer TA, Hirschberg K, Zaal KJ, Lippincott-Schwartz J: ER-to-Golgi transport visualized in living cells. Nature 1997, 389:81-85.

92. Horio T, Oakley BR: The role of microtubules in rapid hyphal tip growth of Aspergillus nidulans. Mol Biol Cell 2005, 16:918-926.

93. Taheri-Talesh N, Horio T, Araujo-Bazán L, Dou X, Espeso EA, Peñalva MA, Osmani SA, Oakley BR: The tip growth apparatus of Aspergillus nidulans. Mol Biol Cell 2008, 19:1439-1449.
94. Abenza JF, Pantazopoulou A, Rodríguez JM, Galindo A, Peñalva MA: Long-distance movement of Aspergillus nidulans early endosomes on microtubule tracks. Traffic 2009, 10:57-75

95. Fischer R, Zekert N, Takeshita N: Polarized growth in fungi - interplay between the cytoskeleton, positional markers and membrane domains. Mol Microbiol 2008, 68:813-826.

96. Harris SD: Cell polarity in filamentous fungi: shaping the mold. Int Rev Cytol 2006, 251:41-77.

97. Momany M: Polarity in filamentous fungi: establishment, maintenance and new axes. Curr Opin Microbiol 2002, 5:580-585.

98. Hubbard MA, Kaminskyj SG: Rapid tip-directed movement of Golgi equivalents In growing Aspergillus nidulans hyphae suggests amechanism for KIF1A-like kinesin and dynein organizes early endosomes in the fungus maintenance of membrane organelle distribution. J Cell Biol 1997, 139:469-484.

99. Aniento F, Emans N, Griffiths G, Gruenberg J: Cytoplasmic dynein dependent vesicular transport from early to late endosomes. J Cell Biol 1993, 123:1373-1387.

100. Hoepfner S, Severin F, Cabezas A, Habermann B, Runge A, Gillooly D, Stenmark $H$, Zerial M: Modulation of receptor recycling and degradation by the endosomal kinesin KIF16B. Cell 2005, 121:437-450.

101. Burkhardt JK, Echeverri CJ, Nilsson T, Vallee RB: Overexpression of the dynamitin (p50) subunit of the dynactin complex disrupts dyneindependent delivery of growth-related materials. Microbiology 2008, 154:1544-1553.

102. Steinberg G: On the move: endosomes in fungal growth and pathogenicity. Nat Rev Microbiol 2007, 5:309-316.

103. Wedlich-Soldner R, Straube A, Friedrich MW, Steinberg G: A balance of KIF1A-like kinesin and dynein organizes early endosomes in the fungus Ustilago maydis. EMBO J 2002, 21:2946-2957.

104. Ton VK, Rao R: Functional expression of heterologous proteins in yeast: insights into $\mathrm{Ca} 2+$ signaling and $\mathrm{Ca} 2+-$ transporting ATPases. Am $J$ Physiol Cell Physiol 2004, 287:C580-C589.

105. Jiao C-Y, Delaroche D, Burlina F, Alves ID, Chassaing G, Sagan S: Translocation and endocytosis for cell-penetrating peptide internalization. J Biol Chem 2009, 284:33957-33965.

doi:10.1186/s12934-014-0117-0

Cite this article as: Martín: Calcium-containing phosphopeptides pave the secretory pathway for efficient protein traffic and secretion in fungi. Microbial Cell Factories 2014 13:117.

\section{Submit your next manuscript to BioMed Central and take full advantage of:}

- Convenient online submission

- Thorough peer review

- No space constraints or color figure charges

- Immediate publication on acceptance

- Inclusion in PubMed, CAS, Scopus and Google Scholar

- Research which is freely available for redistribution
C Biomed Central 